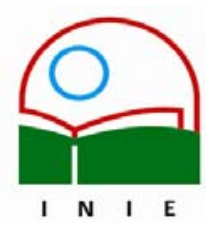

Universidad de Costa Rica

Facultad de Educación

Instituto de Investigación en Educación

ACTUALIDADES INVESTIGATIVAS EN EDUCACION

\title{
ENGLISH TEACHERS AS MATERIALS DEVELOPERS
}

\section{Marlene Ramírez Salas ${ }^{1}$}

Resumen: Este artículo enfatiza la necesidad de que los profesores de Inglés crean y adapten sus propios materiales. La autora presenta la definición de Desarrollo y Adaptación de Materiales, su proceso y algunos ejemplos elaborados por ella misma para ilustrar el tema.

Palabras clave: DEFINICIÓN DE DESARROLLO Y ADAPTACIÓN DE MATERIALES/ PROCESO DE DESARROLLO DE MATERIALES DIDACTICOS/ EJEMPLOS/

Abstract: This article focuses on the need for English language teachers to become materials developers. The writer presents a definition of Materials Development and Adaptation, the process to follow to develop and/or adapt teaching materials, and some samples created or adapted by the writer to illustrate the topic.

Key words: DEFINITION OF DEVELOPMENT AND ADAPTATION OF WORKING MATERIALS / DEVELOPMENT OF LEARNING MATERIALS / EXAMPLES

A fundamental underpinning in the process of English teaching is Materials Development and/or Adaptation. For many years, English teachers have been using their textbooks and teaching materials faithfully; however, in many cases, these materials do not reflect the reality of the classroom in terms of the students' English proficiency level, interests, wants and needs. As Block states (1991) "despite the bounteous harvest of ELT materials which the past decade and a half has provided, published materials do not always provide the type of texts and activities that a teacher is seeking for a given class" (p. 211). English teachers might feel that something is missing in regards to materials, and they do not know what and how to provide them. Fortunately, Materials Development and/or Adaptation is a teaching topic that has recently caused great concern among English teachers as a way to bridge the gap between what the current English textbooks offer and what the learners really need in their learning environment. In fact, many undergraduate and graduate programs offer Materials Preparation as a core course to train English teachers in this area; nonetheless,

\footnotetext{
${ }^{1}$ Bachiller en Inglés de la Universidad de Costa Rica y Master en la Enseñanza del Inglés como Lengua Extranjera de Southern Illinois University. Labora para la Universidad de Costa Rica desde 1993 en la Escuela de Lenguas Modernas impartiendo cursos a nivel de Bachillerato, Licenciatura y Maestría.
}

Correo eléctronico: marami@racsa.co.cr

Artículo recibido: 23 de junio, 2004

Aprobado: 23 de agosto, 2004 
very few books have been published which investigate this issue and which could provide written information and feedback to English teachers. With this idea in mind, the writer intends to provide a practical guide to the different aspects of the process of materials writing for an EFL classroom. This article presents a definition of what Materials Preparation is, the characteristics required for developed and/or adapted materials, the process of developing materials, the importance of layout, and finally, some sample activities developed and/or adapted by the writer to illustrate the topic.

\section{Definition of Materials Development and Adaptation}

As a starting point, it is important to define Materials as anything used by teachers or learners to facilitate the learning of a language. Materials could obviously include cassettes, videos, CD-Roms, DVD's, dictionaries, grammar books, readers, workbooks, photocopied exercises, all kinds of realia, lectures and talks by guest speakers, Internet sources, and so on. (Tomlinson, 1998, p.2 ) This spectrum of teaching resources has indeed opened up to other types of materials contrasting with the old idea that language teaching materials were just the course books. Kitao (1998) also defines materials "as the center of instruction and one of the most important influences on what goes on in the classroom" (p. 1). Undoubtedly, this definition represents a great responsibility on the part of the teachers who must seriously consider what materials to use in their classrooms.

Another basic and very essential concept that calls out for definition is Materials Development. Tomlinson (1998) refers to it as

anything which is done by writers, teachers or learners to provide sources of

language input and to exploit those sources in ways which maximize the likelihood

of intake: in other words the supplying of information about and/or experience of the language in ways designed to promote language learning. (p. 2)

To the previous definition I would add that Materials Development encompasses any kind of activity and/or exercise (games, role plays, readings, problem-solving situations, group discussions, etc.) totally developed from raw texts, with or without pedagogical purposes, for the students' level and created to address a section of the course content, that seems to be weak or lack further development or practice. Materials Development ranges from creating a short grammar exercise to writing a complete textbook.

Within the concept of Materials Development, there is a commonly used term that also needs to be defined: Materials Adaptation. It refers to the application of some strategies to make the textbook more effective and flexible. These strategies are omission, addition 
(adding extra material), reduction, extension (lengthening an activity to draw attention to other language features), rewriting / modification, replacement, re-ordering, and branching (offering alternative ways to do the same activity, e.g. drawing, writing, preparing a speech, looking for a song). (Maley, p. 281) Contrasting with Materials Development, when teachers adapt an activity or exercise from a textbook, they use that activity or exercise as the basis to make certain changes. The text is the same given in the textbook, but exploited and used differently. I would say that this is the process that many teachers usually follow in their classes, since they can use old textbooks to take texts and ideas and adapt them to their current teaching needs. Both processes are indeed time-consuming and time-demanding; however, Materials Adaptation is "easier" in the sense that teachers can use texts given in different textbooks, whereas in Materials Development everything must be created from scratch.

\section{Reasons to develop / adapt materials}

Some teachers may question the need to develop or adapt teaching materials if everything they need is already in a textbook elaborated by people who really know. Being this a very valid opinion, it is necessary to analyze the positive and negative aspects of using a textbook, and from there, discuss the need to develop and adapt materials. O'Neil (1990) states that

books provide a grammatical and functional framework from within we could work. It is a nonsense to argue that this framework is never the same from one group to another even though the ultimate, specific uses two groups may make of language may differ. The framework is as much a result of the language itself as it is of the learner's needs. (...) Almost always a textbook can be found which will provide the core language which is necessary and useful for a group whose needs may at first seem unique. (p. 150)

The textbook, together with the syllabus, (not to mention some language courses in which the textbook itself constitutes the syllabus) is the backbone that holds up a language course. In a textbook, teachers do find an appropriate sequence to follow and a support to base their daily teaching. Textbooks are good outlines that teachers can follow and adapt to their teaching, cultural, and institutional needs.

Course books also provide a source and a guide for students. If students have missed a class, have problems with a certain language aspect, want to review, practice, reinforce, or just know what comes ahead, they can find that information in the textbooks. As 
O'Neil (1990, p. 151) says "textbooks are a resource for staying in touch with the language". Students need a source to lean on, to consult and to revise anytime they feel suit. Besides this, in textbooks, students find information nicely presented and elaborated. Nobody can deny that the layout of most textbooks is unquestionably neat and with great graphic art. Students have in their textbooks wonderful pictures, charts, drawings, organization of information, and so on, presented in the best ways possible. O'Neil also mentions that home-made materials tend to get shabby very quickly and, even in these days of high-quality photocopiers and word-processors, cause enormous production and storage problems. (...) The fact that books are bound means they are easy to carry and to look at where and when learners want, on buses, at meal time, in parks, while waiting for appointments, etc. No other medium is as easy to use as a book. (p. 153)

Although very skillful teachers can work on a decent course packet, they will be many steps behind when compared to a textbook. Harmer (2003) points out another important element in a textbook. He says that

textbooks provide a sensible progression of language items (...) Textbooks can be systematic about the amount of vocabulary presented to the student. (...) Good textbooks also relieve the teacher from the pressure of having to think of original material for every class. (p. 257)

Throughout my teaching experience, I have felt that a course without a textbook is very similar to a ship without a clear destination. It may navigate days and nights and arrive at many ports, but if the route is not clearly set, important ports can never be reached, precious time can be wasted, and eventually, the ship can get completely lost.

However, textbooks can also have an adverse effect on teaching. As it was mentioned before, textbooks indeed constitute the backbone of a language course; however, much more needs to be done to complement what textbooks already bring. Edge and Wharton (1998) suggest that "experienced teachers do not tend to follow the script of a course book inflexibly. They add, delete and change tasks at the planning stage, and they reshape their plans during the lesson in response to the interaction that takes place" (p. 300). Many times a textbook presents the material in a way that does not fit the reality of the classroom or the current needs of the students. It is in this moment where the teacher has to define what to change, eliminate, add or extend. In fact, this is what keeps a class alive. If teachers over-use a textbook over a period of time, they will find themselves teaching the same type of activities in the same order repeatedly. In such a situation, even with good 
textbooks, students may find the study of English becoming a routine and thus less and less motivating. (Harmer, 2003, p. 257) Teachers should really avoid getting involved in this rigid sequence by providing students with supplementary material developed or adapted to their needs. I am totally aware that most teachers are under considerable pressure because they are forced to comply with a syllabus and they teach many classes. They are also influenced by the attitude of the institution and those colleagues who see the textbook as a resource that has to be closely followed. But the reality also forces teachers to find ways to spice up their classes without falling into a dangerous and tedious routine, as Karpova (1999) suggests,

Many textbooks create a climate for socially isolated learning. They contain

information centered on exercises such as repetition, pattern practice drills, gap

filling, and grammatical transformation. Teachers need more materials that help

students become thoughtful participants in a socially rich environment for learning

and that feature everyday uses of English. (p. 1)

Undoubtedly, one way of getting students much more involved in their learning process and of transforming them into active participants is by incorporating Materials Development / Adaptation into our daily teaching.

Another reason teachers have to develop / adapt materials is the fact that even though a textbook provides a framework, as cited by O'Neil, this framework needs to be contextualized. Textbooks present materials, such as maps, flight and bus schedules, opening and closing times of public services, prices, names of cities, information about public or famous personalities that our students may not be familiar with. As Block (1991) says instead of having students look at fictitious facts about a fictitious person, they could be given facts about a politician or entertainer, known to students. (...) The fact that the students are talking about something as real as their home town makes the practice activity much more relevant, and engaging. (...) Abstract knowledge constructs about common day-to-day experiences, the general framework of which, over time, can usefully be internalized by students. (p. 213-214)

Contextualization makes learning significant to students by helping them become interested and aware of what happens around them.

Undeniably, Materials Development / Adaptation is very time-consuming. Sometimes teachers may even wonder what to prepare materials for if they are going to be used only once. This is totally true, especially if we choose certain taped programs from the radio or TV which may become outdated within 24 hours, or even less. But apart from this, teachers should realize that if it takes them long hours to create an activity, this activity should be 
recycled along the school year with different levels of difficulty and groups. Based on my personal experience, I do believe that even if teachers use their own developed activity only once, it is well worth the try when good results are obtained and motivation among the students is increased, not to mention the teacher's great feeling of satisfaction to present something created by herself/himself. In this respect, Block (1991) comments that

the personal touch in teacher- generated materials is highly appreciated by students. When students realize that the teacher has gone outside the course book and prepared something personally, they make remarks such "Oh, you work hard." ( $p$. 214)

I have even received comments like, "You're very creative" or "You really like what you do because you have beautiful materials." If I have been told all these nice words, why can other teachers not experience the same?

\section{Characteristics of developed / adapted materials}

When talking about Materials Development / Adaptation, there are some important features to take into account in the process of creating or adapting teaching materials. Among the many characteristics mentioned by Tomlinson (1998), there are four that I consider fundamental and thus worth discussing. The first one is the fact that materials should have an impact on the students and arouse learners' curiosity, attention and interest. By impact Tomlinson refers to materials that make use of different types of sources (TV, newspaper, Internet sites, radio, magazines, letters), have an attractive presentation and appealing content (1998, p. 7). Obviously, to achieve this, teachers should clearly know his/her students and his/her objectives to develop / adapt an activity for a particular teaching aspect. These materials ought to be relevant, useful and focused on what students are learning at that point.

A second characteristic is exposure to real language which is attained by giving students opportunities to use language in real-life communicative activities. By having guest speakers, radio interviews, lectures, class surveys, spontaneous conversations, projects, interviews to other teachers, group discussions, and panels in class students can be exposed to real language. The materials should also stimulate learner's interaction with the input rather than just having passive reception of it. This does not necessarily mean that the learners should always produce language in response to the input, but it does mean that they should always do something mentally or physically in response to it. (Tomlinson, 1998, p. 13) 
Following directions, filling out an application form, chart or table with important information are examples of receptive activities in which students are processing authentic language. It is very important for teachers to ask themselves every time they create or adapt an activity how much real language students are using and/or producing in that particular activity. If the answer is not much, then, it is time to restructure or eliminate that activity.

As a third feature, materials should address different learning styles and intelligences. If teachers know their students, they will design activities in which students can really feel at ease using their learning preferences and abilities. Teachers should develop/adapt materials for visual, auditory or tactile students as well as activities for students with bodily-kinesthetic, musical, linguistic, logical mathematical, spatial, interpersonal, intrapersonal, and naturalistic intelligences. Of course, it would be very difficult, though not impossible, to include in one activity all these styles and intelligences, but along the school year teachers can address one or two styles or intelligences in different activities. As Maley (1998) points out, "I would particularly like to see more use made in materials development of what we know about the value of engaging emotions in the learning process" (p. 280). Language learners do need to feel that language is not just a tight body of grammatical structures, rules and words, but a vehicle in which they can use their abilities and preferences to make their learning process much easier and enjoyable.

As Richards and Rodgers (2002) mention

Multiple Intelligence thus belongs to a group of instructional perspectives that focus on differences between learners and the need to recognize learner differences in teaching. Learners are viewed as possessing individual learning styles, preferences, or intelligences. Pedagogy is most successful when these learner differences are acknowledged, analyzed for particular groups of learners, and accommodated in teaching. (p. 115)

As an illustration of this point, part of the content of the first year English major course, LM-1001 Integrated English 1, deals with topics related to family and clothing. For the family topic, one of the activities that I asked my students to do in class was to draw their family tree. For the clothing topic, I also asked my students to create a collage of dressing fashions and trends with magazine cut-outs. I would have never imagined the wonderful creations my students came up with. They learned the language and used it in class to describe what they did to their classmates, and they used their imagination and creativity to design amazing 
projects. My students even told me that those activities were very useful for them because they learned many important linguistic aspects by having fun and using their abilities.

The last, but not the least, important feature of Materials Adaptation is the guidance towards students' autonomy and independence. The latest trends in EFL teaching support and encourage the idea that students need to learn to be responsible for their own learning and to know that they can do activities in and out of class by themselves. Edge and Wharton (1998) stated that "in order to achieve this in class teachers need to encourage the learners to reflect on what they are doing and why" (p. 296). Giving students CHOICES is a key element in making them autonomous and independent. Students need different alternatives to go over a specific task. Of course, the one alternative that learners choose is likely to be closely related to their intelligences, learning styles, and learning strategies. If teachers create and/ or adapt teaching materials, they should offer choices, or at least, more than one possible way to complete the task. Going back to the previous projects of the family tree and clothing collage, students were given specific directions, but they had endless avenues to accomplish the final outcome. Obviously, not all activities are so open as to give students many choices like information gap activities, but teachers should make an effort to provide students with chances to feel part of the decision-making process of what to do and how to do it.

\section{Process of Materials Development and / or Adaptation}

Like many teaching situations that follow a clear process, Materials Development and Adaptation is not the exception. Jolly and Bolitho (1998, p. 98-99) present a very self explanatory and easy-to-follow process to apply when creating or adapting teaching materials. The process is as follows: 
1. IDENTIFICATION: by the teacher or learners of a need to fulfill or a problem to solve by the creation of materials

2. EXPLORATION: of the area of need/problem in terms of what language, what meaning, what functions, what skills?

3. CONTEXTUAL REALIZATION: of the proposed new material by the finding of suitable ideas, contexts or texts with which to work.

4. PEDAGOGICAL REALIZATION: of materials by the finding of appropriate exercises and activities and the writing of appropriate instructions for use.

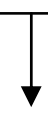

5. PHYSICAL PRODUCTION: of materials, involving consideration of layout, type size, visuals, reproduction, tape length, etc.

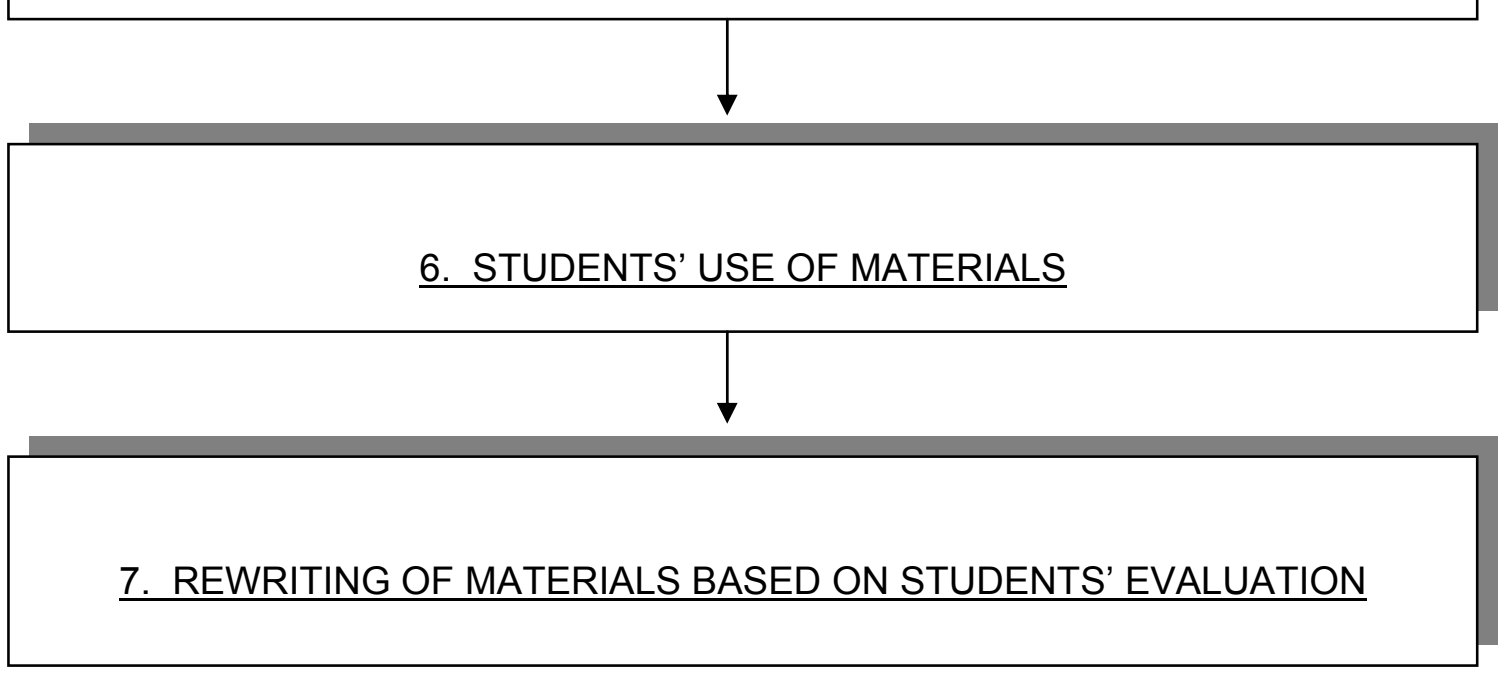


Even though Jolly and Bolitho present a simple process, it is still hard for me to understand or follow that process for more practical purposes. When this happens, I try to use questions to make the process easier and more direct. For this reason, I have added some questions that, throughout my teaching career, I have considered very helpful, not just for myself but for my Licenciatura and Master's students who really get the idea of the process very clearly and fast. Each of the questions corresponds to each step above:

Step 1: Do I really need other materials in this section? If the answer is YES (which in most of the cases happens) continue with the next question

Step 2: What can I do here?

Step 3: Where can I find information helpful to create / adapt something for this linguistic aspect?

Step 4: What kind of exercises can I do here to exploit the idea or the text better?

Step 5: What is the best way (layout) to present my activity?

Step 6: Was the activity useful? Did I achieve my goal? Did my students like it? Do I have to add, eliminate, correct, clarify, simplify, or rearrange something in this activity?

I do consider that the process mentioned before lacks one important phase which is the revision and feedback from colleagues. I would place this step just after the physical production of the materials, that is, between steps 5 and 6 . As language teachers, we need to share our ideas and receive feedback that can enlighten and guide us to a better performance. When we create something, we consider it so perfect that we are unable to see some flaws that may cause an unsuccessful outcome. This is the moment in which our colleagues play an important role by giving us comments or new ideas which may radically change our perspective, and consequently, our entire activity. I do believe that as developers of teaching materials, we cannot use something in class if we have not had enough feedback from our colleagues beforehand. Undoubtedly, the process seems to be very simple at first glance; however, its application is difficult and time-consuming, but very rewarding.

\section{Importance of materials' layout}

In the process outlined previously, step 5 deals with the physical production of materials. However, this aspect is not explained in detail in the few books and articles written about Materials Development and Adaptation. Indeed, this is a fundamental phase which 
developers have to pay careful attention to. Students must receive the final product neatly presented, but the word "neatly" does not refer just to the presentation as such, but to instructions, spelling, use of language (grammar, word choice, word order), use of pictures, font size, and use of space. It is not that the aesthetic element of an activity is not important; obviously, students like colorful papers and creative ways to play with space in a handout. Nonetheless, this aspect seems irrelevant when the activity is full of mistakes, has disorganized information and presents incorrect content.

Instructions are fundamental to the successful outcome of an activity. As Harmer (2003) points out, "instructions must be short, simple, concise, and precise. They should never mislead learners or make them feel frustrated along the process of completing an activity" (p. 154).

Another essential feature of an activity is spelling and language use. Everything teachers give their students is a model that students will imitate or copy. If that model is wrong, misspelled and with mistakes, what can teachers expect from their students? Teachers should be very meticulous about this aspect and make sure that whatever is given to their students must be perfect. This is the moment in which colleagues are very helpful in pinpointing mistakes that are imperceptible to the developer's eyes.

Pictures are also an important element in materials' layout. They are commonly used in many activities; however, teachers have to look for pictures that are appealing, clear and big enough. Sometimes copies of pictures are very dark and students have a hard time making sense out of them. Color pictures are very useful to elicit information from students. Also, pictures must be closely related to the topic of the activity. Indeed, pictures are not space fillers; they do need to have a direct connection with the activity.

If teachers are doing lots of cut-and-paste from different sources, they should wipe out all black lines, unrelated information, or page numbers that may confuse the students. Space and font size are also important in the development of an activity. Students need space to write down and visual space between one step and the next one. In most of the cases, because of budget limitations, teachers try to save money by putting lots of information in small spaces, creating a very unattractive and overfilled page. However, for layout reasons and for the sake of the learners' eyes (and the teachers' too) an activity should be done with a comfortable reading font size (14 or 16) and with plenty of space for students to see the different sections and / or pictures, graphics, charts, and tables of the activity. It has been my perception that students easily get lost when they are presented with too much information at once. They do need time to digest the information, and visual space provides this. It is a 
fact that due to technological limitations teachers sometimes cannot type their activities, and they present them in a handwritten way. I do not see any problem with this, as long as the handwriting is clear and neat to avoid confusion and time spent on endless clarifications. Finally, I would like to emphasize the obligation of giving credit to the source(s) teachers are getting ideas or information from. Anything teachers use to create or adapt must be mentioned at the bottom of the activity with a small font size (9-10) to avoid distracting students' attention. This will also enable teachers to locate the source of an activity easily for other teaching purposes.

\section{Samples of Materials Development and Adaptation}

In this section the writer will present two samples of activities. One totally original and another one adapted from a teaching source. The first activity is to be used originally with low intermediate students to practice the past tense. This activity was designed by the author and a colleague of hers. Applying the process created by Jolly and Bolitho, the developers wanted to find an activity to encourage students to practice the past tense in a more authentic and personal way. The results of the search were not very convincing, and the same activities were found in many sources such as the typical questions: What did you do last weekend? Where did you go last vacation and what did you do? and the chronological ordering of a story in past tense, among others. Therefore, the developers decided to come up with an activity themselves. Although simple, they have had great results from it and students like it a lot. Students receive the following written information:

1. Get in groups of three.

2. On a big sheet of paper, draw a big pizza pie.

3. Draw 13 slices inside the pizza pie.

4. Individually, think about three important dates / events in your life.

5. Choose three slices.

6. Write only one date / event on each slice.

7. Leave four slices blank.

Once step 7 is ready, the teacher goes around and writes on the four slices left the following information: START, Last Christmas, Last Birthday Party, Last Vacation. Another possibility, which saves a lot of time, is to use stickers already prepared with these four phrases. The pizza pie will look like this: 


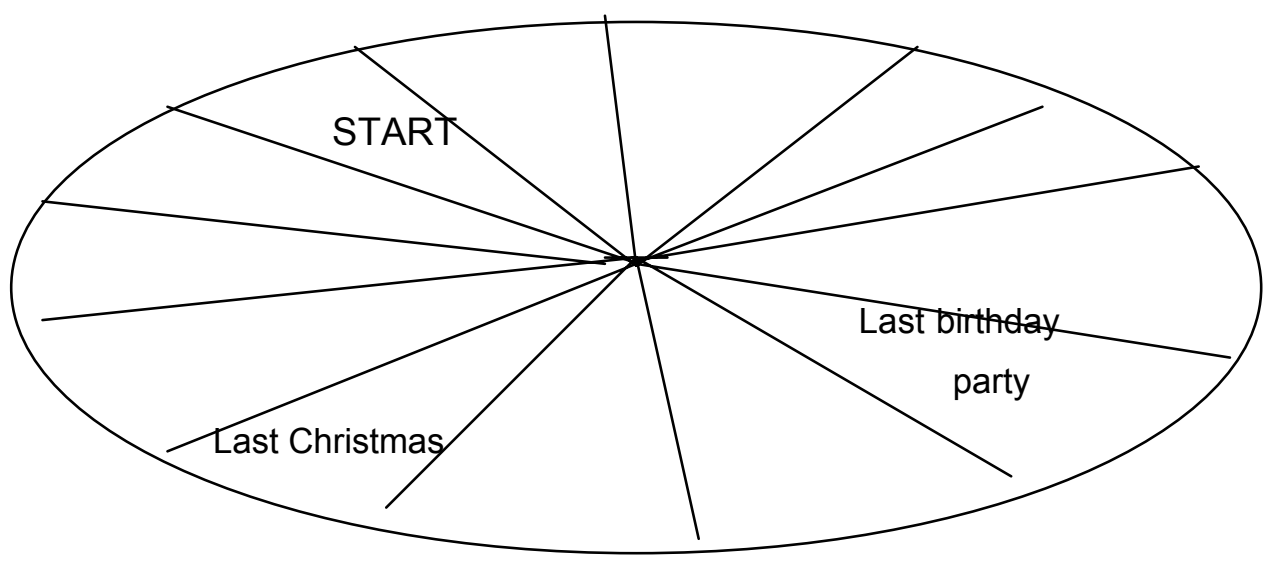

Then students continue with the next step.

8. Choose something small (a token) to represent you in this game and put it on the slice that says START.

9. Toss the dice.

10. Start counting the number you have in the dice.

11. If you fall on your own date or event, wait until your classmates ask you questions about that day.

12. If you fall on your classmate's date or event, ask him/her questions like:

What happened that day? Why is it so special for you?

Where were you? Who was with you? What did you do that day?

13. If you fall on any of the slices that say Last Christmas, Last Birthday Party, Last Vacation tell your classmates how you celebrated those moments and what you did that day. Give as much information as possible.

One characteristic of this activity is that students prepare the pie themselves, so I can observe their strategies and the way they organize their groups to draw the chart and follow the directions. I also notice how they explain the instructions to each other. Besides this, students get to talk about their own lives and personal experiences. They can see the applicability of what has been explained and practiced in class and how they can use the past tense in their daily context. Underneath this simple activity, there was a subtle but important application of the Multiple Intelligence Theory with the bodily-kinesthetic intelligence (drawing the pie), the spatial intelligence (how to divide the pie in 13 slices, and the visual help of the pie), the intrapersonal intelligence (thinking about their dates / events), and the interpersonal 
and linguistic intelligence (talking and explaining about their own lives). There was also the reviewing of a very difficult grammatical pattern in a very free and independent way, and the use of contextualized and authentic tasks. Another feature of this activity is that it is reusable. This idea can be applied to many linguistic aspects like conditionals, present perfect, present perfect progressive, future; reviewing topics in class, discussing current events, news, and cultural issues among others.

The second activity shows an adaptation I made from a very good book named Great Ideas (1991) by Leo Jones and Victoria Kimbrough for high intermediate or advanced students. The original activity is as follows:

You live in a neighborhood where the Big Burger Company wants to open a new hamburger restaurant. You and your neighbors do not want the restaurant. Talk to the representatives of Big Burger, and tell them why you don't think the restaurant is a good idea. Some reasons might be:

1. The building is ugly.

2. The area around the restaurant will be very noisy.

3. Everything at BB is fried and very unhealthy. Fast food isn't good for you.

4. There will be a lot of garbage - this may attract rats and make the neighborhood smell bad.

5. There are enough places to buy lunch already.

I wanted to use this idea for a topic about complaining, giving excuses and solutions. Jones and Kimbrough's idea is good, but I wanted something more contextualized and tied to the students' real life. I decided to take the same idea and I designed an activity about a mall, and instead of an activity for two groups, I added some extra information to divide my class into three groups so that each particular group had different roles. In this way my students can work in smaller groups and their chance to talk increases. The adapted idea looks like this:

Group 1: $\quad$ You live in Barrio El Carmen known as a very quiet, clean, and safe neighborhood. The Big Mall Company wants to open a new mall in El Carmen. You and your neighbors are members of the neighborhood committee. After long meetings, you have come to the conclusion that a mall is not a very good idea. Talk to the representatives of The Big Mall and the City representatives, ask them some questions, and tell them what you think. 
Some of your arguments might be:

1. There are many malls already.

2. The property can be used for a park instead.

3. The area will be very noisy, polluted and dangerous.

4. The construction area is too big for that community.

5. Traffic jams will get worse in rush hours with this mall.

6. Others

Group 2: You are the representatives of the Big Mall Company (BM). You want to open a new mall in Barrio El Carmen. You are talking to the members of El Carmen neighborhood and the City representatives. Try to convince them that the mall would be a good idea.

Some of your arguments might be:

1. The mall will create new job opportunities.

2. It will increase the security in the community.

3. The value of the properties will increase.

4. People will have a closer place to go shopping.

5. The company will create traffic facilities like bridges for pedestrians and other car routes.

6. Others

Group 3: You are the City representatives of Barrio El Carmen belongs to. You have been called to a meeting where the Big Mall Company and El Carmen neighborhood committee will discuss the positive and negative aspects of opening a new mall in town. After listening to both positions and asking questions, give or deny the permit to open the mall.

Some of your questions might be about:

1. Opening and closing hours.

2. Collecting and treatment of garbage, especially the one from fast food restaurants.

3. Recycling program and sanitation measures

4. Security system of the building

5. Use of space (parking lots, green areas)

6. Economic benefits for the community

7. Others

Each group has to prepare their ideas, complaints, questions, arguments and solutions very carefully, and then, the discussion starts. At the end, the Municipality members have the final decision and based on the other groups' arguments, they decide whether or not 
to open the new mall and under what conditions. The teacher takes notes while the discussion is going on, and later she/he gives feedback about language use.

With this activity, students have to come up with strategies and ideas to organize their information and to decide what each member says and when. They practice turn taking and language expressions to agree and disagree, to ask for clarification and questions, and to restate and summarize previous explanations. All of this is practiced in the activity, and it is very necessary in real life situations. Autonomy, contextualization and authenticity are indeed present in this activity.

The writer wanted to share these two activities as samples of Materials Development and Adaptation in Grammar and Speaking skills. Obviously, this process can be applied to any of the macro skills (listening, speaking, reading, and writing) and micro skills (vocabulary, grammar, and pronunciation) in teaching a second or foreign language. An important element that teachers cannot forget is that for any kind of activity that they adapt or create for any of the macro or micro skills, students do need preparation and follow up (pre and post activities).

\section{Conclusion}

No one can deny that developing and adapting materials is difficult and demanding, but it is necessary in order to offer our language students other avenues and alternatives to practice the target language in more authentic and independent ways. Materials development and adaptation does not belong only to book writers and publishers. Mainstream English teachers can create and adapt materials with a little of extra time, motivation, creativity, and love. It is indeed a process that with practice and trial and error methods becomes more and more rewarding and necessary in our teaching contexts. It is also a way of keeping ourselves updated in new teaching trends and ideas. As Tomlinson states (1998)

We need to make efforts to discover reliable and valid information about the sort of materials teachers and learners want to use. We need to innovate and experiment if we really want to find out how we could make language learning materials more effective and motivating. (p. 158)

Our language classes cannot stick to only one book. We have the responsibility and obligation to look for other ideas, to try them out, and see what we can get and improve from 
them. So, what are we waiting for? Let's start creating and adapting materials to lighten up our class and cast routine and boredom away.

\section{References}

Block, D. (1991). Some Thoughts on DIY Materials Design. ELT Journal, 2 (45): 211-216.

Edge, J; and Wharton, S. (1998). Autonomy and development: living in the materials world. In B. Tomlinson (Ed.), Materials Development in Language Teaching. New York: Cambridge University Press. 295-310.

Harmer, J. (2003). The practice of English language teaching. New York: Longman.

Jolly, D. and Bolitho R. (1998). A framework for materials writing. In B. Tomlinson (Ed.), Materials Development in Language Teaching. New York: Cambridge University Press. 90-115.

Jones, L., \& Kimbrough, V. (1991). Great ideas. New York: Cambridge University Press.

Karkova, L. (April / May 1999) Considering the following when selecting and using authentic materials. Tesol Matters, 9 (2): 55-59.

Kitao, K. (1998). Selecting and developing teaching / learning materials. Retrieved in October 2001, de Kkitao@mail.doshisha.ac.jp

Maley, A. (1998). Squaring the circle - reconciling materials as constraint with materials as empowerment. In B. Tomlinson (Ed.). Materials Development in Language Teaching. New York: Cambridge University Press. 279-294.

O'Neil, R. (1990). Why use textbooks? In R. Rossner \& R. Bolitho (Eds.). Currents of Change in English Language Teaching. New York: Oxford University Press. 148156

Richards, C and Rodgers, T. (2002). Approaches and Methods in Language Teaching. New York: Cambridge University Press.

Tomlinson, B. (1998). Materials Development in Language Teaching. New York: Cambridge University Press. 